\title{
Clinical Features and Management of Some Muscular Disorders in Children - A Brief Review
}

\author{
Dwi Putro Widodo
}

(Department of Child Health, Medical School University of Indonesia, Jakarta)

\section{Introduction}

Study has proven that electrical activity of resting and contracting skeletal muscles and conduction of the nerre impulse have become one of the most useful diagnostic tools in neurology. EMG arıd nerve conduction studies have become indispensable in the diagnosis and management of peripheral nerve and muscle disease (neurological differential diagnosis).

Muscle disease of childhood is a heterogeneous group of disorders that, as a whole, are relatively common but individually often quite rare. This is a perplexing group of disorders. The descriptions of many of the muscular dystrophes and congenital myopathies sound very similar. All patients seem to have congenital hypotonia and proximal weakness. Fortunately, the historic and clinical feature are often quite distinct, allowing for fairly accurate diagnosis at the bedside or in the clinic. ${ }^{1}$

Disorders of skeletal muscle can be divided into five broad categories: (1) muscular dystrophies, (2) congenital myopathies, (3) disorder of ion channels, (4) metabolic myopathies, and (5) acquired disorders of muscle. This paper will discuss clinical features and management aspects of a few of muscle disorders in the group of muscular dystrophies and disorder of ion channels.

\section{Congenital Muscular Dystrophy}

Congenital muscular dystrophy (CMD) is a heterogeneous entities and characterized by autosomal recessive inheritance, early onset hypotonia, multiple joint contractures,

Aulhor's address: Dr. Dwipoutro Widodo, Department of Child Health, Medical School, Universily of Indonesia, Jakarta, Jalan Salemba 6, Jakarta 10430, Indonesia, Tel 62-21-3907742, Fax 3907743. 
and dystrophic changes in muscle. The condition tends to remain relatively static, but some subjects may show progression whereas others may have actual functional im: provement and pass various motor milestones and achieve the ability to walk. ${ }^{2}$

In general, two broad groups can be distinguished by the presence or absence of abnormalities of brain formation evident on neuro-imaging studies or on autopsy examination of the brain (Table 1)

Table 1. Congenital muscular dystrophy: Specific varieties

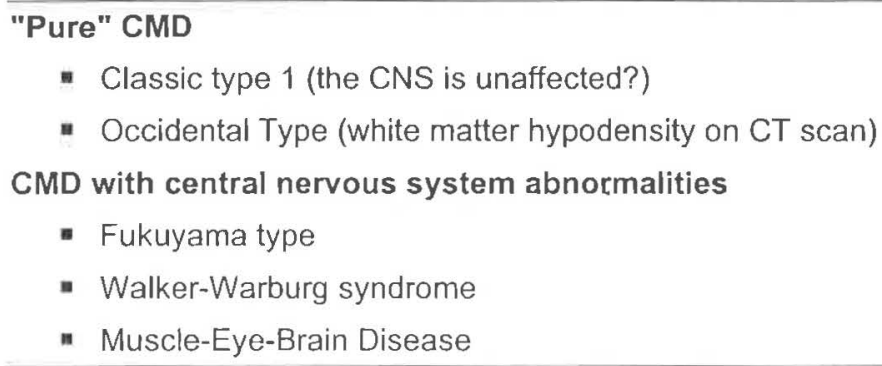

The illness is apparent at birth and usually is striking in its manifestations. The most common features are facial weakness, variable in severity, diffuse hypotonia, and weakness. The weakness particularly involves the neck, and defective head control, especially of flexion, is a very consistent feature. Limb weakness often exhibits the pattern typical of muscle disease; proximal muscles are more affected than distal ones and in general arms are more impaired than the leg. ${ }^{5.6}$ Contractures and sometimes arthrogryposis may be present at birth. More commonly, contractures are not striking at birth but develop rapidly postnatally. Kyphoscoliosis of the thoracolumbar spine occurs in $1 / 3$ of the patients and congenital dislocation of the hip is present in approximately $25 \%$ of cases. Less common features are disturbances of swallowing and ventilatory function at the time of presentation.

The clinical course in CMD has ranged from slow improvement to inexorable progressive into death. However, in the largest study with the longest follow-up (most between 8 and 16 years), the disease was reported to be ultimately progressive in all. ${ }^{5}$ Involvement of diaphragm and intercostal muscle developed later in infancy and childhood, and approximately $1 / 3$ ultimately died of respiratory failure.

\section{Pure CMD (Classic type 1 and Occidental Forms)}

The pure classical form includes cases with normal or subnormal intelligence and with normal cranial scan. In some children there may be mild mental retardation, 
seizure, or EEG abnormality and cerebral white matter hypodensity may be seen even in patients without clinical apparent CNS manifestations. ${ }^{1}$ In the occidental type, IQ is normal or subnormal, there are white matter hypodensity, cortical atrophy and/or ventricular dilatation on CT scan examination. The occidental type may tend to run a more severe course in the presence of significantly higher CK level. Multiple joint contractures and muscle fiber necrosis were seen in more occidental patients ${ }^{4}$ (Table 3 ).

\section{Fukuyama type CMD}

The typical features are associated with mental retardation and seizures. Inherited as an autosomal recessive trait, Fukuyama type CMD (FCMD) is the second most common muscular dystrophy in Japan, after Duchenne muscular dystrophy.

The diagnostic criteria for FCMD include onset before the age of 8 months, generalized hypotonia and weakmess, delayed motor development, diminish or absent retlexes, and facial muscle involvement. Ocular manifestations may occur but are not usually as severe as in the Walker-Warburg syndrome. Joint contractures are not noted in infancy but become evident early in course of the disease. Hip and knee contractures are present by the age of 3 years, but eventually all joints may be affected. Disability is usually severe, and few children are able to walk. The average age of death is 18 years. $^{1}$

The CNS manifestations are mental retardation, which is often but not invariably severe, and febrile or non-febrile seizure. White matter hypodensities and cerebral atrophy with ventricular dilatation are demonstrated by CT scan in more than $50 \%$ of cases. Micropolygyria of the cerebrum and cerebellum is the most consistent CNS finding at autopsy; it is thought to be due to a defect in neuronal migration.

\section{Walker-Warburg Synd'rome}

Walker-Warburg syndrome (WWS )is a lethal autosomal recessive disorder that is manifest by brain, muscle, and eye abnormalities. The diagnostic criteria include type II lissencephaly, cerebellar malformation, retinal malformation, and CMD. Other congenital abnormalities include cleft lip/palate, small penis, and undescended testes. There is significant mortality in the perinatal period. Infants who survive are usually profoundly retarded and may have seizure. Median survival is less than 1 year.

\section{Muscle-Eye-Brain Disease}

There is a considerable overlap between Muscle-Eye-Brain Disease (MEB) disease and WWS, it has been suggested they are a single disease varying in severity.

As with the other CMDs, severe hypotonia and weakness are noted in infancy, and development milestone are significantly delayed. Contractures can be marked but 
Table 2. Clinical features of patient with $C M D^{1,4,6}$

\begin{tabular}{lcccccc}
\hline & \multicolumn{2}{c}{ Pure CMD } & & FCMD & WWS & MEB \\
\cline { 2 - 4 } & Type 1 & Occidental & & & \\
\hline Congenital hypotonia and weakness & $100 \%$ & $100 \%$ & $100 \%$ & $100 \%$ & $100 \%$ \\
Facial weakness & $11 / 18$ & $15 / 20$ & $(+)$ & $(+)$ & $(+)$ \\
Joint contracture & $14 / 18$ & $15 / 20$ & $4 / 6$ & $(+)$ & $1 / 4$ \\
$\quad$ At birth & $8 / 18$ & $11 / 20$ & $1 / 6$ & $(+)$ & $1 / 4$ \\
$\quad$ At later stage & $6 / 18$ & $4 / 20$ & $4 / 6$ & $(+)$ & $1 / 4$ \\
$\quad$ Multiple & $7 / 18$ & $14 / 20$ & $(+)$ & $(+)$ & $(+)$ \\
Consanguinity & $12 / 18$ & $14 / 20$ & $0 / 6$ & $(+)$ & $1 / 4$ \\
Rapid progressive course & $(-)$ & $(-)$ & $4 / 6$ & $(+)$ & $3 / 4$ \\
Motor delay & $100 \%$ & $100 \%$ & $100 \%$ & $100 \%$ & $100 \%$ \\
CNS involvement & & & & & \\
$\quad$ Mental retardation & $4 / 13$ & $2 / 13$ & $100 \%$ & $100 \%$ & $100 \%$ \\
$\quad$ Convulsions & $(-)$ & $(-)$ & $2 / 6$ & $(+)$ & $1 / 4$ \\
$\quad$ Macrocephali & $(-)$ & $(-)$ & $1 / 6$ & $(+)$ & $2 / 4$ \\
$\quad$ Hydrocephalus & $(-)$ & $(-)$ & $4 / 6$ & $(+)$ & $3 / 4$ \\
Encephalocele & $(-)$ & $(-)$ & $0 / 6$ & $(+)$ & $3 / 4$ \\
Ophthalmologic disorder & $(-)$ & $(-)$ & $(+)$ & $(+)$ & $4 / 4$ \\
\hline
\end{tabular}

some patients also develop spasticity. Dysmorphic facies are common. Severe myopia and visual failure are consistent ocular abnormalities; other eye signs include congenital or infantile glaucoma, retinal dystrophy, nystagmus, uncontrolled eye movement, and cataract. Generalized seizures are common. Survival into the sixth decade is reported.

\section{Management}

Because the course is non progressive for the years in many of the cases, it is important to attempt to correct existing contractures by physical therapy, i.e., passive stretching or serial splints, and to prevent development of contractures by active and passive exercise. 


\section{Myotonic Dystrophy}

Myotonic dystrophy (MyD) is a multisystem disease, in contrast to the other myotonic syndromes. MyD is the most frequent and disabling of the myotonic syndrome. Although myotonia is the hallmark of this disorder, it is usually a minor nuisance compare with other signs and symptoms. The typical clinical feature is unmistakable, but diagnostic difficulties can arise because of the great variability of clinical expression, which ranges from the severe congenital form of MyD to normal clinical examination (Table 3).

Table 3. Classification of MyD: correlations of clinical signs with age of onset ${ }^{7}$

\section{Mildest}

Onset: middle to old age

Major findings: cataracts, minimal or no muscle abnormality

\section{Classic}

Onset: adolescence and early adult life

Major findings: Myotonia, muscle weakness (e.g. face, forearms, and foot dorsiflexor)

\section{Congenital}

Onset: at birth, frequent history of hydramnios and reduce fetal movement

Major findings: respiratory distress, hypotonia, bilateral facial weakness, feeding

difficulties, talipes, mental retardation

In the majority of cases, onset of symptoms and diagnosis occurs in the late teens. The full-blown picture is readily recognizable and the muscle weakness commonly include ptosis and facial weakness as well as wasting of the sternocleidomastoids and involvement of distal rather than proximal limb muscles. There may be associated swallowing difficulties and dysarthria and some cases have an external ophthalmoplegia.

Myotonia may be an early symptom and often affects the hands, with inability to release a grasp. In the course of the disease, the muscle weakness soon becomes the predominant problem, to be followed by respiratory or cardiac problems. Cataracts are common in the late stages of the disease but may be detected in earlier cases on slip lamp examination. 
The classical adult type may be recognized in childhood in affected families. These children are often symptom-free at this stage but myotonia may be demonstrated either clinically or on EMG and they also usually show a myopathic facies. Mild degrees of facial muscle weakness can often be demonstrated by the inability to screw the eyes up tightly and completely bury the eyelashes. The children subsequently follow the classical course of the disease with progression of weakness and also myotonia. Children initially may be seen because of subnormal intelligence and delayed development. Occasionally, premature cataracts, pulmonary and gastrointestinal, gynecological /obstetrical problems will initiate medical evaluation.

\section{Management}

Supportive therapy for muscle weakness, serial evaluation to check for cardiac arrhythmia and respiratory insufficiency during, and careful pre-and postoperative monitoring of patients. Pregnancy and delivery pose special risks for mother and their offspring. ${ }^{7}$ Myotonia can be ameliorated with quinine and phenytoin or other anticonvulsant drugs. But myotonia is only rarely a bothersome symptom; it is the weakness that is disabling, and little can be done about that.

\section{Congenital Myotonic Dystrophy}

Congenital myotonic dystrophy (CMyD) is an inherited disorder of muscle that exhibits a number of distinctive differences from myotonic dystrophy of adult patient. The hallmark of congenital myotonic dystrophy is hypotonia, rather than myotonia, as observed in adult patient. The congenital form of myotonic dystrophy was first described clearly by Vanier in $1960 .^{8}$

\section{Clinical features}

The disorder is usually apparent in the first hours and days of life. Certain characteristic of pregnancy often precede the neonatal disorder, Spontaneous abortion or premature birth occurs in the most severely affected infants. Reduced fetal movement and polyhydramnios is a common characteristic of the pregnancy. ${ }^{9,10}$ The clinical fétture in the neonatal period are usually marked and characteristic.

The most striking feature are generalized hypotonia, facial diplegia, respiratory and feeding difficulties invoive both sucking and swallowing, and arthrogryposis (especially of the lower extremities). The facial diplegia imparts the characteristic tent-shape appearance to the upper lip and inability to close the eyes fully. Hypotonia is always accompanied by weakness and, interestingly in approximately $90 \%$ of cases, by areflexia or marked hyporeflexia. Atrophy is usually obvious, especially after the first days of life. Myotonia is not a feature of the condition at this stage and is also not detectable 
on EMG. ${ }^{11}$ Clinical myotonia, elicited by percussion of such muscle as the deltoid, has been detected ás early as 3 hours of age, but usually is not readily elicited until later in infancy. ${ }^{8}$

CMyD is only seen in the offspring of mothers who themselves have the adult variant of myotonic dystrophy, even though the mother may be only mildly or minimally affected. Paternal transmission of neonatal-onset myotonic dystrophy is very rare, occurring in only 3 of 70 cases. ${ }^{9}$ The diagnosis is made essentially on clinical grounds and is based on a combination of the above-mentioned symptoms. It can only be confirmed by detecting evidence of myotonia on clinical examination and the EMG of the mother.

\section{Clinical course}

The biphasic course of CMyD is characteristic of the disease. The immobility, hypotonia, respiratory and feeding difficulties always diminish after a few weeks. But several years later the same symptoms as those seen in adult variant of myotonic dystrophy arise, including myotonia, muscle atrophy and cataract. Neonatal mortality is high, approximately $40 \%$, in the severely affected patients. Unlike the general improvement in neonatal feeding and in respiratory difficulties, facial diplegia usually becomes more obvious as baby fat disappears; ptosis often becomes apparent as well. Muscle weakness, which initially is generalized or more marked proximally, begins to assume the distal preponderance characteristic of the adult disease. Clinical myotonia become elicitable later in infancy and is present in the majority of patient after the age of 5 years. ${ }^{9}$ Impairment of motor and intellectual development is apparent in the first weeks of life. mental retardation is essentially invariable in infants with CMyD who survive the neonatal period. ${ }^{10}$

\section{Management}

Attention to the early respiratory problems is important. The swallowing difficulties is usually self-limiting and the majority will achieve the ability to suck and swallow by about 2 months of age. The associated deformities should be actively treated and can often be managed with no surgical approach. ${ }^{2}$

\section{Myotonia Congenita}

The myotonia congenitas (MCs) are non dystrophic disorders with myotonic stiffness as their predominant symptom. They occur in autosomal dominant (Thomsen's disease) and autosomal recessive (Becker's disease) forms. Generalized painless myotonia is the major clinical feature of both forms. Symptoms appear in the first or second decade of life. Myotonic stiffness develops with sudden physical exertion the follows a 
period of rest. Repeated muscle contraction results in resolution of the myotonic stiffness, the so called "warm-up". There is a wide range of severity and variation in muscle involved. Legs are most consistently involved. Patient with autosomal recessive may also complaint of weakness.

Myotonia is easily elicited in many different muscles. Exposure to cold may exacerbate the myotonia. In Becker's disease, progressive weakness and more severe myotonia can occur over time. Both forms have notable muscle hypertrophy. In Thomsen's disease, myotonia is frequently noted in infancy, as opposed to the mid childhood, insidious onset in Becker's disease. When myotonia is noted in infancy, the diagnosis is more likely a form of myotonia congenita than congenital myotonic dystrophy, in which patients rarely show myotonia clinically or electrically early in life. Myotonia may not develop until 5 years of age or later. Men appear to be more severely affected than women. ${ }^{12}$

Extramuscular manifestations are not seen in MC. In both forms of MC patients may try to conceal their disease. The life span of patients with either form of MC is not shortened by the disease. In Becker's disease, there is transient weakness that appears for a few seconds during the initial attempt at performing a specific movement following a period of sustained inactivity and muscle strength improve to normal after several strong contractions (Table 4). ${ }^{7}$

\section{Management}

Treatment of MC is directed toward relief of the myotonic stiffness. Treatment of myotonia is not always necessary, but when it is, the most effective medications are those that stabilize the muscle. Phenytoin is frequently the first choice because it has more benign side effect profile than other drugs and a reasonable response rate $1 .{ }^{2}$ More recently, the oral lidocain derivatives, tocainide and mexiletine, have proven to be the most successful treatment. ${ }^{7}$ 
Table 4. Characteristics features and therapy for myotonic disorder in childhood ${ }^{7,12}$

\begin{tabular}{|c|c|c|c|}
\hline \multirow{2}{*}{$\begin{array}{l}\text { Clinical } \\
\text { features }\end{array}$} & \multirow[t]{2}{*}{ Myotonic Dystrophy } & \multicolumn{2}{|c|}{ Myotonia Congenita } \\
\hline & & Dominant & Recessive \\
\hline Inheritance & Dominant & Dominant & Recessive \\
\hline $\begin{array}{l}\text { Mechanism for } \\
\text { myotonia }\end{array}$ & Unknown & Chloride Channel & Chloride Channel \\
\hline Age of onset & $\begin{array}{l}\text { Broad range of ages } \\
\text { (infancy to adult life); } \\
\text { with infant onset in most } \\
\text { severe cases }\end{array}$ & $\begin{array}{l}\text { Infancy to early } \\
\text { childhood }\end{array}$ & $\begin{array}{l}\text { Late childhood, } \\
\text { occasionally starts } \\
\text { earlier } \\
\text { or begins in teens }\end{array}$ \\
\hline $\begin{array}{l}\text { Mental } \\
\text { retardation }\end{array}$ & yes & no & no \\
\hline $\begin{array}{l}\text { Extramuscular } \\
\text { manifestation }\end{array}$ & yes & no & no \\
\hline Myopathy & $\begin{array}{l}\text { Face, eyes, forearm, } \\
\text { hands, and legs, with } \\
\text { generalized weakness } \\
\text { and hypotonia }\end{array}$ & $\begin{array}{l}\text { Muscle hypertrophy } \\
\text { frequent; no } \\
\text { myopathy although } \\
\text { variants hypertrophy }\end{array}$ & $\begin{array}{l}\text { Occasional muscle } \\
\text { weakness can occur late; } \\
\text { hypertrophy of muscles } \\
\text { frequently occurs in legs }\end{array}$ \\
\hline Myotonia & $\begin{array}{l}\text { Primary affects hand and } \\
\text { forearm muscle, and } \\
\text { tongue occasionally } \\
\text { affects respiratory } \\
\text { muscle and smooth } \\
\text { muscle such as intestine } \\
\text { or uterus }\end{array}$ & $\begin{array}{l}\text { generalized stiffness, } \\
\text { especially after rest; } \\
\text { improve with exercise; } \\
\text { prominent myotonia } \\
\text { of eye closure; but not } \\
\text { paradoxical myotonia }\end{array}$ & $\begin{array}{l}\text { generalized stiffness, } \\
\text { esp. after rest; transient } \\
\text { weakness is prominent } \\
\text { after complete relaxation } \\
\text { for several minute; } \\
\text { myotonia occur in eye; } \\
\text { no paradoxical myotonia }\end{array}$ \\
\hline $\begin{array}{l}\text { Provocative } \\
\text { stimuli }\end{array}$ & $\begin{array}{l}\text { Myotonia worsened by } \\
\text { rest and cold; myotonia } \\
\text { is relatively constant in } \\
\text { severity and muscles } \\
\text { affected }\end{array}$ & $\begin{array}{l}\text { Prolonged rest or } \\
\text { maintenance of the } \\
\text { same posture }\end{array}$ & $\begin{array}{l}\text { Prolonged rest or } \\
\text { maintenance of the } \\
\text { same posture }\end{array}$ \\
\hline $\begin{array}{l}\text { Therapy for } \\
\text { symptoms }\end{array}$ & $\begin{array}{l}\text { Bracing; cataract removal; } \\
\text { monitor arrythmias and } \\
\text { respir. insufficiency;pace- } \\
\text { maker; phenitoin or mexi- } \\
\text { letine; avoid depol. mus- } \\
\text { cle relaxant and barbitu- } \\
\text { rates, surgery. }\end{array}$ & $\begin{array}{l}\text { Exercise; antimyotonia } \\
\text { therapy, e.g. mexile- } \\
\text { tine; Achilles tendon } \\
\text { streching help prevent } \\
\text { need for heel cord } \\
\text { lengthening surgery }\end{array}$ & $\begin{array}{l}\text { Exercise, especially } \\
\text { avoiding prolonged rest; } \\
\text { antimyotoni therapy e.g. } \\
\text { exiletine; transient } \\
\text { weakness does not } \\
\text { improve after mexiletine }\end{array}$ \\
\hline
\end{tabular}




\section{References}

1. Cwik VA, Brooke MH. Disorder of muscle-dystrophies and myopathies. In Berg's Principles of child neurology, 1st ed. New York: McGraw-Hill 1996;1665-776.

2. Dubowitz V. Muscle disorder in childhood, 2nd ed. Philadelphia: WB Saunders 1995;93-104.

3. Bonnemann CG, McNally EM, Kunkel LM. Beyond dystrophin: current progress in the muscular dystrophies. Curr Opinion Pediatr 1996; 8: 569-82.

4. Topaloglu H, Kale G, Yalnizoglu D, et al. Analysis of 'pure' congenital muscular dystrophy in thirty eight cases. How different is the classical type 1 from the occidental type cerebromuscular dystrophy. Neuropediatrics $1994 ; 25: 94-100$.

5. McMenamin JB, Becker LE, Murphy EG. Congenital muscular dystrophy. A clinicopathological report of 24 cases. J Pediatr 1982; 100: 692-7.

6. Leyten QL, Gabreels JM, Renier WO, et al. Congenital muscular dystrophy. J Pediatr $1989 ; 115: 214-21$.

7. Moxley III RT. Myotonic disorders in childhood: Diagnosis and treatment. J Child Neurol 1997; 12:116-29.

8. Volpe JJ. Neurology of the newborn 3rd ed. Philadelphia: WB Saunders 1995; 509-16.

9. Harper PS. Congenital myotonia dystrophy in Britain. Clinical aspect. Arch Dis Child 1975(a); 50:505-513.

10. Hageman ATM, Gabreels JM, Liem KD, et al. Congenital myotonic dystrophy. A report on thirteen cases and a review of the literature. J Neurol Sci 1993; 115:95-101.

11. Harper PS. Myotonic Dystrophy, 2nd ed. Philadelphia: WB Saunders, 1979; 20-34.

12. Gutmann L, Phillips LH. Myotonia congenita. Semin Neurol 1991;11:244-8. 